\title{
7 \\ Nachtrag: Der Brief des Bruders
}

\section{Inhaltsverzeichnis}

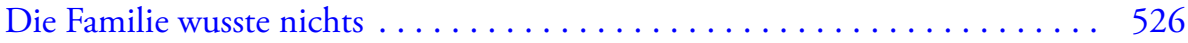

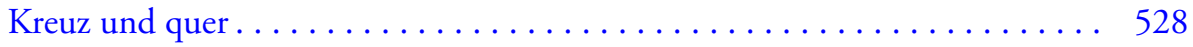

Schwierig?................................. 530

Zwei Töchter - über Vater und Onkel. .................. 531

Zwei Söhne - über Vater und Onkel . . . . . . . . . . . . . . . 532

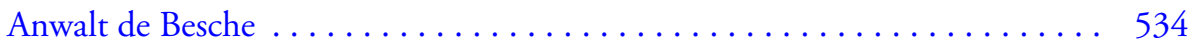

Mit offenem Visier . . . . . . . . . . . . . . . . . . . . . 536

Kinder $\operatorname{im}$ Bett . . . . . . . . . . . . . . . . . . . . . . . 538

Schweizer Pflichten . . . . . . . . . . . . . . . . . . . . 541

Pendeln zwischen Außenpunkten . . . . . . . . . . . . . . . . . . 543

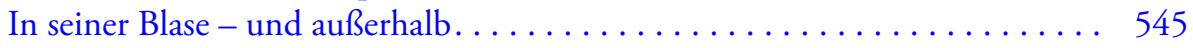

Über ein halbes Jahrhundert jung und begeistert. . . . . . . . . . . . . . . 547

Sonnenenergie und Akupunktur . . . . . . . . . . . . . . . . . . . . 549

Für immer zweiundzwanzig. .................... 550

Eines Tages, als ich bereits eine Weile an diesem Buch schrieb, lag ein weißer länglicher Umschlag auf meinem Schreibtisch. Der Brief war adressiert an: Rolf Widerøe, 5415 Nussbaumen, Schweiz. Abgestempelt in: Alicante, Spanien. 1994. Absender: Viggo Widerøe. Er war geöffnet. Im Inneren befanden sich zwei, mit der zitternden Hand eines alten Mannes dicht beschriebene Bögen. Auf der ersten Seite, oben in der einen Ecke, stand geschrieben: „Sehr wichtiger Brief von Viggo.“ Rolfs ältester Sohn Arild 
hatte den Brief zwischen den hinterlassenen Papieren seines Vaters gefunden und meinte, den müsse ich sehen.

Der Inhalt war tatsächlich aufsehenerregend. Das Aufsehenerregendste bestand darin, dass er für den Sohn neu war. Späterhin sollte sich zeigen, dass auch kein anderer in der Familie davon wusste. Es drehte sich um etwas, worüber sie kaum gesprochen hatten, in gewisser Weise aber doch etwas wussten: das Verhältnis zwischen den Brüdern Rolf und Viggo während des Krieges.

Arild hatte Waloscheks Buch über den Vater gelesen, worin stand, dass die Deutschen den Bruder als Trumpfkarte verwendet hätten, um ihn zu überreden, mit nach Deutschland zu kommen, und dass die Deutschen gesagt hätten, als Gegenleistung versuchen zu wollen, die Haftbedingungen für den Bruder zu erleichtern. Einige wenige Zeilen auf den Seiten 5 und 63 in Rolfs Biografie. Verfasst von einem deutschen Physiker. Das war also das Konkreteste, woran sich die Familie halten konnte. Als Tor Brustad einige Jahre später seine Untersuchungen im Norwegischen Zentralarchiv vornahm, wurden dort die Angaben im Buch bestätigt, dass Rolf gehofft habe, seinem Bruder helfen zu können. Aus dem Buch ging jedoch nicht hervor, in welchem Maße Rolf dies gelungen war. Aber er hatte es versucht. Der Bruder überlebte. Das war in Kürze das, was die Familie wusste bzw. gewusst hatte, seit Waloscheks Buch 1993 erschienen war. In den fünfzig Jahren, die in der Zwischenzeit zuvor vergangen waren, hatten sie nicht einmal das gewusst.

Dann tauchte der Brief auf. Im Sommer 2007. Der Brief vom Bruder an den Bruder, der so viel erklärt und dennoch so wenig sagt. Oder, anders ausgedrückt, der so viel sagt und so wenig erklärt:

„Erst jetzt verstehe ich all deine enormen Bemühungen, um mir während des Krieges zu helfen. Im Hinblick auf die Geschehnisse ist ziemlich sicher, dass deine Bemühungen gewirkt haben."

Und ein Stück weiter heißt es:

„Ich wurde in den Garten verlegt und war dort der einzige Gärtner. Den niemand kontrollierte."

Keine großen Worte, keine Fakten, keine Umarmungen. Hier spricht die Nüchternheit. Nach all diesen Jahren des Schweigens ist des Dramas genug.

Damit ist es also doch ans Tageslicht gekommen, und das im Klartext: Rolf hat ihm während des Krieges wirklich geholfen. Jetzt hat er es erfahren. In seinem 92. Lebensjahr. Nicht weil Rolf es selbst erzählt hat, sondern weil 
ein Buch erschienen ist, in dem es zu lesen ist. Viggo lässt Rolf in dem Brief wissen, dass er es jetzt weiß. Der Bruder ist über 90. Als es geschah, waren sie um die vierzig. Seither haben sie geschwiegen. Sich ihren Teil gedacht. Und geschwiegen. Einander im Urlaub besucht und gemeinsam mit Kindern und Enkelkindern gelacht und es sich gemütlich gemacht. Hatten den Krieg zurückgelassen. Am besten so. Sich mit dem Leben abgefunden. Miteinander. Vielleicht auch mit sich selbst. Damals geschah so viel Seltsames. Lass uns weitergehen, einen Strich ziehen. Es bringt nichts, darin zu wühlen. Es wird eh niemand verstehen. Und dann, an einem Februartag, während Norwegen und die ganze Welt mit den Olympischen Spielen in Lillehammer beschäftigt sind, stellt sich heraus, dass nicht einmal sie selbst sich über alles im Klaren waren.

„Erst jetzt verstehe ich es“, schreibt Viggo. Du warst es, Rolf, der dafür gesorgt hat, dass ich im Gefängnis überlebt habe. Für einen alten Mann in Oslo fallen Teile des Puzzles seines Lebens an ihren Platz. Ein großer Bruder in seinem Lieblingssessel in der Schweiz kann mit Sicherheit konstatieren, dass der Bruder jetzt Bescheid weiß. Keiner von ihnen musste sich mehr die Frage stellen. Danke, Gott, dass die Boulevardpresse nicht da war. Einige direkte Sätze zwischen der Entschuldigung, sich noch nicht für das Weihnachtsgeschenk bedankt zu haben, Gerede von blühenden Mandelbäumen und einem „Kommt ihr im 'Winter' zu Besuch?“. Das klärt sich.

Dann können sich andere wundern. Aber so war es. Hier folgt der Brief, der Viggos Dankesschreiben für das neu erschienene Buch war, das Rolf seinen Geschwistern zu Weihnachten nach Oslo geschickt hatte:

\section{Übersicht}

$8 / 2-94$

Lieber Rolf,

herzlichen Dank für den langen Weihnachtsbrief. Ich wünsche dir und deiner Familie für das neue Jahr alles Gute. Du klagst über ein schlechtes Gedächtnis, aber der Brief deutet nicht darauf hin! Ich hoffe, ich habe mich für zwei Bücher über dein Leben bedankt. Das eine hat Else bekommen. Erst jetzt hatte ich Zeit, das ganze Buch zu lesen. Konnte Pedro W. nicht danken, habe seine Adresse nicht, aber du musst ihm meinen Gruß ausrichten. Grüße von Egil Amundsen, der von deinem Werk sehr beeindruckt war. Er mochte das Buch, weil es so ehrlich und gut geschrieben war.

Erst jetzt verstehe ich all deine enormen Bemühungen, um mir während des Krieges zu helfen. Im Hinblick auf die Geschehnisse ist ziemlich sicher, dass deine Bemühungen gewirkt haben. Zuerst wurde ich von N-Ost ganz in den Süden von Darmstadt geschickt, Dreibergen. Leute mit zehn Jahren Gefängnis waren selbstverständlich gefährlich und durften nicht draußen arbeiten. 
Am selben Tag, als ich im Gefängnis ankam, wurde ich zum Chef gerufen, einem Major der alten Schule.

Wir redeten nett über Norwegen und unsere Kultur. (Er hasste Hitler sicher.) Nach einigen Monaten anstrengender Arbeit auf den Feldern kam er zur Inspektion ins Lager. Ich wurde von der Arbeit zu ihm hineingerufen und hatte erneut ein nettes Gespräch mit ihm - er hieß übrigens Mohr.

Kurz darauf wurde ich von der anstrengenden Arbeit in den Garten versetzt und war dort der einzige Gärtner. Den keiner kontrollierte. Baute u. a. Tabak an, den enge Freunde bekamen. Im letzten Winter war es Waldarbeit, aber die Wachen begriffen, wohin das führte, und pfiffen nahezu auf die Arbeit und auf uns.

Im März kamen die Amerikaner, und ein Teil von uns übernahm das Lager (2200 Mann) und wickelte es im Laufe einer Woche ab. Anschließend wurde ich Dolmetscher und Sekretär in General Pattons Militärregierung und hatte viele seltsame Aufträge in ganz Hessen. Schloss Banken, entließ den Vorstand und eröffnete sie wieder mit neuem Vorstand und Unmengen von Geld, angeblich in den USA hergestellt. -

Hatten seit dem 14/11 fast die ganze Zeit Sonne und Sommer. Jetzt blühen die Mandelbäume. Kommt ihr im 'Winter' zu Besuch?

Gruß an die ganze Familie

Viggo

P.S. Kürzlich war das 60 -jährige Jubiläum der Fluggesellschaft in Bodø. Es wurde ein Heft über die Entwicklung erstellt, das ich sie gebeten habe, dir zu schicken.

Vier kleinen Abschnitten über die Zeit in Gefangenschaft folgt ein Abschnitt über die Befreiung durch die Amerikaner. In der Form genauso undramatisch. War all das für Rolf wirklich neu? Hatte er keine Übersicht darüber, in welchen deutschen Lagern der Bruder gewesen ist? Wusste er nicht, dass Viggo während des Zweiten Weltkriegs einem der bedeutendsten amerikanischen Generäle gedient hatte, dem Panzergeneral Patton? Bevor er Ende Mai 1945 nach Hause kam. Einiges davon muss neu gewesen sein, ansonsten hätte es Viggo wohl nicht als Sachinformation in einen sonst knappen Brief aufgenommen, obwohl dies sicher ein Versuch war, das Ganze auch für sich selbst zusammenzufassen.

Es ist erlaubt, sich zu wundern.

\section{Die Familie wusste nichts}

Auch der Rest der Familie kannte den Inhalt des Briefes bis dato nicht. Hing es so zusammen? Dass es Rolf also gelungen war, dem Bruder zu besseren Haftbedingungen zu verhelfen? 
Alles, was sie vorab durch Waloscheks Buch erfahren hatten, waren zwei kleine Abschnitte:

„In der Hoffnung, seinen Bruder Viggo - ein Pionier der norwegischen Luftfahrt, der sich am Widerstand beteiligt hatte - aus der Haft in Deutschland zu befreien, akzeptierte es Rolf Widerøe im Jahr 1943, seinen Jugendtraum, einen 'Strahlentransformator' oder 'Betatron' in Hamburg zu bauen, mit dem man sehr starke Röntgenstrahlen erzeugen konnte. "1

Wenig später wird etwas ausführlicher erklärt, wie es begann:

„Als wir dann im Grand Hotel waren, fragten Sie mich, ob ich mit ihnen nach Berlin kommen würde. Sie meinten, daß es von Bedeutung für meinen Bruder sein könnte. (...) Die deutschen Offiziere deuteten an, daß mein Bruder eventuell freigelassen werden könnte, wenn ich ihnen helfen würde. Dies war für mich entscheidend, und ich willigte ein, nach Berlin mitzukommen. "2

In dem Buch finden sich keine Angaben darüber, woraus der eventuelle Einsatz bestanden hatte oder ob er erfolgreich gewesen war. Zu lesen ist jedoch, dass Rolf Viggo im Gefängnis besucht hatte. Viggos Tochter Turi dazu: ${ }^{3}$

„Ich weiß, dass Onkel Rolf Vater in mehreren Gefängnissen in Deutschland besucht und dass er versucht hat, ihm zu helfen, freizukommen. Etwas Konkretes ist dabei nie herausgekommen."

Einige Wochen nach der Buchveröffentlichung schrieb Viggo den Brief mit der Information, dass er das Buch gelesen habe und mit eigenen Augen erkennen konnte, dass der Bruder ihm wirklich geholfen hatte. Die Bestätigung dessen, dass es so gewesen ist, wie er es im Grunde geglaubt hatte. Aber erst als der Brief in Rolfs hinterlassenen Papieren gefunden wird, erfährt der Rest der Familie davon. Erneut hatten die beiden geschwiegen. Sie waren fertig damit. Längst versöhnt. Sie hatten nicht alles wissen müssen. Was der eine oder der andere gesagt, getan, gedacht oder gewusst hatte, war nicht wichtig. Sie wollten nach vorn schauen und Frieden miteinander halten. Freunde sein. Der Brief zeigte, dass das richtig war. Dann wurde er weggelegt. Mit dem Vermerk: „Sehr wichtiger Brief von Viggo.“ Gefunden wurde er 2007.

Heute ist es nicht leicht zu verstehen, warum enge Familienmitglieder nicht längst über die Fakten orientiert waren, ja nicht einmal die beiden, die es betraf. Denkt man jedoch darüber nach und versucht sich in die 
Umstände während des Krieges hineinzuversetzen, mit Ausnahmezustand in allen Lebensbereichen, ist es vielleicht nicht ganz so merkwürdig. Traf man sich kurz nach dem Krieg zu Familiengeburtstagen, ist es vielleicht verständlich, wenn man es unterließ, bei Kaffee und Kuchen über Grausamkeiten und Gefängnisaufenthalte zu sprechen. Und ist eine Weile vergangen, dann will man das Ganze vielleicht nicht wieder neu beleben. Einige versuchen zu vergessen und erhalten dafür Hilfe. Entkommen der Erinnerung. Das hat mit Respekt zu tun. In einer „schönen“ Familie vielleicht mit einer Zugabe von aristokratischem Stolz. Und vielleicht ein wenig Furcht. Das ist das eine. Das andere ist, dass man nicht über das sprach, was man während des Krieges getan hatte. Schlicht und einfach. Man tat Dinge, weil sie getan werden sollten. Lernte, nicht zu fragen.

Ein weiterer Grund, warum es nicht so verwunderlich ist, dass die Familie nichts wusste, ist so naheliegend, dass er beinahe nicht in die Betrachtung einbezogen wird. Menschen sind verschieden. Familien sind verschieden. Es ist üblich zu denken, dass eine Extremsituation Eigenarten verstärkt. Wenn das Nichteinmischen, das Respektieren der Integrität und der Grenzen des anderen eine Familientugend ist. Wenn Toleranz großgeschrieben wird. Und Bildung. Ja, dann ist es ganz selbstverständlich, dass ohne den Hintergedanken, etwas zurückzuhalten, dennoch Geheimnisse entstehen.

\section{Kreuz und quer}

Wie es in großen Familien mit vielen Kindern und Schwiegerkinder in Kriegstagen oft der Fall war, verliefen die Trennlinien kreuz und quer. Ressourcenstark, wie die Widerøe-Familie war, befand sich viel im Gange und Familienzusammenkünfte und Geburtstage sollten mit Rücksicht in alle Richtungen stattfinden. Einige waren auch im Ausland oder verreist oder aus anderen und „besseren“ Gründen nicht abkömmlich. Das ließ die Fronten weniger sichtbar werden. Aber sie waren da. Arild erzählt, dass sie während des Krieges zu großen Anlässen nur selten, sonst aber ganz selbstverständlich die Großeltern in Vinderen besuchten.

„Für meine Eltern aber gab es, unter den Erwachsenen, während des Krieges nicht so viel familiären Kontakt, soweit ich mich erinnere. Nach dem Krieg normalisierte sich das wieder. Recht schnell. Meine Großeltern väterlicherseits, Carla und Theodor, besaßen doch dieses große schöne Wochenendhaus auf 
Skjæløy bei Fredrikstad. Und dort durften wir immer hinkommen. Skjæløy stand uns immer offen."

Im Wochenendhaus waren sie es gewohnt, dass sowohl Große als auch Kleine zu Gast waren, das war der „Zufluchtsort“. Dorthin kamen Tanten und Onkel, Vetter und Cousinen. Späterhin eine weitere Generation und ihre Partner. So vergingen die Jahre und ihnen wurden Dinge klar, die sie zuvor nicht verstanden hatten - entweder weil sie damals Kinder waren oder weil nicht darüber gesprochen wurde. Eine Portion Vernunft und Nüchternheit, ein wenig Bildung und Respekt, eine lange Tradition des Zusammenhalts und viel Liebe taten das Ihrige. Und wie immer tat auch die Zeit das Ihrige. Die Familie ist sich einig, dass die Schwierigkeiten längst vorüber sind. Keiner leugnet, dass es anstrengend war. Aber es ist vorüber. Dazu sagt Thor Spandow, Sohn von Rolfs Schwester Else:

„In der Familie gab es immer einen sehr guten Zusammenhalt, in allen Generationen. Mein Onkel Viggo, der im Jerpefaret am Holmenkollåsen wohnte, kam nach der Arbeit mehrfach pro Woche kurz vorbei, um seinen Eltern in Vinderen Hallo zu sagen und später seiner Mutter, nachdem sie Witwe geworden war."

Dann erzählt auch er von den Sommern auf Skjæløy, mit seinen Cousinen Kari und Turi (Viggos Töchtern), Unn (Rolfs Tochter), ihren zwei, aus der Schweiz kommenden Brüdern und all den anderen. Der Großmutter, die die Fäden in der Hand hielt, und dem Großvater, der sich sonnte und badete. Tante Grethe, die das Grundstück nebenan bekam, und der Mutter, die das Wochenendhaus der Eltern übernahm:

„Das waren starke Menschen, aber ich habe nie von Feindschaft gehört. Nach dem Krieg gab es wohl einen gewissen Konflikt zwischen Rolf und Viggo, aber sie entschieden sich, darüber hinwegzusehen. So verging die Zeit, und die Familie fand zum Zusammenhalt zurück. Mir wurde im Nachhinein die Geschichte serviert, warum Rolf gegangen war, in der Fassung, wie die Familie es auffassen wollte. Was mir aber meine Mutter erzählte, war, dass er nach Deutschland ging, um seinem Bruder in Gefangenschaft zu helfen. Ich selbst habe mir meine Gedanken darüber gemacht, dass er Wissenschaftler und die Politik betreffend ein Analphabet war. In Norwegen hatte er keine Möglichkeit, sein Projekt zu entwickeln. Die Schwiegerfamilie hatte ihre Art der Bewunderung für Deutschland. Die Sonntagsessen waren in der 
Widerøe-Familie eine Institution, und das muss ab und an schwierig gewesen sein. Tante Solveig, Viggos Frau, war eine Zeit lang selten dort, ebenso Tante Ragnhild. Aber das ist jetzt Geschichte. Alle haben sich entschieden, nach vorn zu schauen." 4

\section{Schwierig?}

Mit Viggo, seiner Frau und vielen anderen, die während des Krieges in die Widerstandsarbeit involviert waren, muss es doch, so werden die meisten denken, für Rolf seltsam gewesen sein, in der Großfamilie in eine normale Situation zurückzufinden. Der Widerstandskämpfer Viggo musste damit umgehen, dass Rolf in eine Familie eingeheiratet hatte, die Nazi-Sympathien hegte. ${ }^{5}$ Wenn der Bruder plötzlich für den Feind arbeitete, während er selbst in Gefangenschaft saß, lautet eine unumgängliche Frage, was das später für das Verhältnis zwischen den beiden bedeutete. Wie auch für die gesamte Familie. Und selbstverständlich war das schwierig und speziell. Fragt man aber heute, sagen sie alle, dass die dramatische Situation nicht zu einer Familienspaltung führte, wie man sie hätte befürchten können. Der Alltag normalisierte sich. Neffe Aasmund Berner drückt es wie folgt aus:

„Rolf und Viggo sorgten auch für Durcheinander. Dass man nicht darüber sprach, tat auch das Seinige. Das war kein Thema, worüber man sprach. Aber dennoch stand es im Raum."

„Aber Rolf hatte doch versucht, dem Bruder zu leichteren Haftbedingungen zu verhelfen?"

„Ja, das habe ich gehört. Einige meinen jedoch, dass konnte auch gegenteilig aufgefasst werden. Darüber wissen andere in der Familie mehr als ich, und nicht alle schätzten die Situation auch gleich ein, anschließend kam es aber auf allen Ebenen zur Versöhnung." 6

Wie denkt Rolfs Schwager Egil Reksten über das Verhältnis zwischen den Brüdern?

„Ich erinnere mich - ich glaube, das war am 90. Geburtstag -, dass Viggo sich fragte, ob er seinem großen Bruder gegenüber zu gemein gewesen war."

"Wie das?"

„Nein, er fand, wenn er darüber nachdachte, dass er nicht so nett gewesen war, wie er es hätte sein sollen."

"Dachte er an etwas Spezielles?" 
„Nein, das glaube ich nicht. Er hatte Rolf gewiss kritisiert, in der Rede irgendwas gesagt, glaube ich, wovon er befürchtete, es könne als Kritik aufgefasst werden - ich erinnere mich nicht mehr daran, was es war."

Ich verweise darauf, dass Rolf Viggo besucht hatte, als dieser in Deutschland im Gefängnis saß.

„Aha? Das wusste ich nicht. Ich weiß auch nicht, wo Viggo eingesessen hat.“

Dann verweise ich darauf, dass sich Viggos Haftbedingungen gegen Ende verbesserten, und frage, ob er wisse, ob das Rolf geschuldet war:

„Nein, darüber weiß ich nichts. Darüber weiß ich überhaupt nichts.“7

Nichts davon war also Gesprächsthema gewesen. Auch deutete nicht viel auf böses Blut zwischen den Brüdern hin, zumindest nichts, woran sich der Schwager noch erinnern konnte?

\section{Zwei Töchter - über Vater und Onkel}

Auch Viggos Tochter Turi Widerøe unterstreicht die Versöhnung und drückt es einfach aus:

„Heute ist die Familie über das Schwierige mit dem Krieg hinweg, hat es hinter sich gelassen, ist versöhnt. “8

Als ihr Vater verhaftet wurde, war sie drei, vier Jahre alt und sagt, sie könne sich nicht erinnern, dass Rolf und ihr Vater ein schwieriges Verhältnis gehabt hätten. Hatten sie es schwer, dann haben sie es für sich behalten.

Ihre Schwester, Wanda Widerøe, die sieben Jahre nach dem Krieg zur Welt kam, beschreibt den Vater als einen Mann des Friedens.

„Vater ließ die Leute Leute sein und sie ihre Leben leben, er war tolerant. Widerstände und Schwierigkeiten schienen ihn nicht zu beeinträchtigen. Er entschied, in seinen Mitmenschen immer das Positive zu sehen. ${ }^{"}{ }^{\prime}$

Ergänzt wird das von der Familienältesten, Rolfs Schwester Else. Für Außenstehende ist es nicht mehr "gefährlich“ zu fragen. Sie erhalten Antwort. 
Rolfs Schwiegervater war Nazi. Rolf war es nicht. Ragnhild war es auch nicht. Rolf arbeitete in der zweiten Hälfte des Krieges in Deutschland. Ja, er war politisch naiv. Ja, die Konsequenzen daraus musste er tragen. Ja, das war eine schwierige Zeit. Aber wir haben da herausgefunden und halten zusammen sehr.

\section{Zwei Söhne - über Vater und Onkel}

Auch Rolfs Söhne muss ich diesbezüglich fragen. Zuerst den ältesten Arild:

"Wie war das Verhältnis zwischen Ihrem Vater und Viggo?"

„Ich weiß nur, als mein Vater 1996 starb, schrieb Viggo an meine Mutter: 'Rolf war ein sehr guter Freund. Er war mein bester Freund.' Und das war nichts, was er einfach so schrieb. So war Viggo nicht.“

"Schrieb Viggo 'Rolf war mein bester Freund'?"

"Ja."

"Wie ich gehört habe, besuchte Rolf Viggo oft in seinem Ferienhaus in Spanien, nachdem sie beide Rentner geworden waren?"

„Ja, in den Jahren, in denen Viggo im Winter in Spanien wohnte, machten sie ständig zusammen dort unten Urlaub."

"Aber er kam nicht zu Rolfs Beerdigung?"

"Nein, aber sie hatten nicht erwartet, dass er in die Schweiz kommen würde. Schließlich war er 92 Jahre alt. Er war auch nicht der Typ, der zu Beerdigungen ging. Das verstehe ich also gut. Am liebsten hätte er auch für sich selbst keine Beerdigung gewollt. Er hielt nichts von der Kirche und den Pfarrern. Das war für ihn nur Heuchelei."

"Ihr Vater aber sah das etwas anders, oder nicht?"

„Ja, mein Vater war religiös, nicht so, dass er regelmäßig in die Kirche ging, absolut nicht. Weihnachten aber, da ging er zum Gottesdienst. In der Anfangszeit fuhren wir nach Deutschland. Hier in der Schweiz sind sie ja Reformierte, und wir waren Lutheraner, deshalb fuhren wir direkt hinter die Grenze, nach Waldshut, und gingen dort in die Kirche. Die gefiel ihm am besten. Dort fuhren wir anfangs immer hin. Später aber wurde es Zürich. Denn dort gab es eine norwegische, ja, man kann es Gemeinde nennen. Und dort gehen mein Bruder und ich Heiligabend noch immer hin, zusammen mit anderen Norwegern und Halbnorwegern. Ansonsten sind wir nicht zusammen, da aber wünschen wir uns fröhliche Weihnachten. Und das ist jedes Jahr das Gleiche. Und dort wird Norwegisch gesungen und gesprochen. Richtige Weihnachtsstimmung. Einige kommen in Tracht und es gibt ein ordentliches 
norwegisches Fest. Auf diese Weise versuchen wir, ein wenig an der Tradition festzuhalten."

Dann frage ich den „kleinen Bruder“ Rolf jr. nach seiner Auffassung des Verhältnisses zwischen seinem Vater und Viggo.

„Darüber kann ich eigentlich nicht so viel sagen. Ich glaube durchaus, dass es ganz gut war. Aber ich weiß nicht, ob es etwas gab, weil Onkel Viggo in Deutschland in Gefangenschaft gewesen ist. Ich weiß es nicht, ich habe keinen richtigen Einblick in dieses Verhältnis. Was ich aber weiß, ist, dass obwohl Viggo sagte, er wolle nie wieder einen Fuß auf deutschen Boden setzen - er flog nur darüber -, so war er absolut sehr, sehr herzlich und sehr gastfreundlich gegenüber allen Freunden, die wir in den Sommerferien mitbrachten, ob sie Deutsche oder Schweizer waren. Er sprach fließend Deutsch mit ihnen und war überhaupt nicht daran interessiert, ihnen zu zeigen, dass er mit dem, was deutsch war, nichts zu tun haben wollte."

Er fügt hinzu, dass viele, denen es während der Besatzung wie den meisten anderen ging, oft klagten und in Selbstmitleid verfielen. Während diejenigen, die wirklich in Gefangenschaft oder im Gefängnis waren und viel Schlimmes erlebt haben, seither nicht darüber sprachen.

„War nicht Onkel Egil auch im Konzentrationslager?“

"Ja, er war fast vier Jahre in deutscher Gefangenschaft. War ein Nacht-undNebel-Gefangener. "

„Darüber hat er nie ein Wort gesagt. Nie. Ich glaube, das ist etwas, worüber man nicht spricht. Vielleicht hat Vater gespürt, dass es mit etwas Widrigem verbunden war, und er deshalb nicht darüber sprechen wollte. Ich weiß es nicht ..."

„Aber Ihr Vater besuchte Viggo im Gefängnis in Deutschland. Zumindest ein Mal. Das habe ich von mehreren gehört. Haben Sie darüber jemals mit Ihrem Vater gesprochen?"

„Nein. Nein. Überhaupt nicht. Darüber habe ich nie mit ihm gesprochen. Zum ersten Mal habe ich davon gehört, als Waloschek anfing, sein Buch zu schreiben."

"Einige behaupten entschieden, dass Ihr Vater versucht hat, die Haftbedingungen seines Bruders zu verbessern."

„Davon habe ich gelesen. Und wissen Sie, was ich da dachte?“

"Nein."

„Ob das wahr ist oder nicht, das weiß ich nicht." 


\section{Anwalt de Besche}

Eine weitere Person soll diesbezüglich zu Wort kommen, nämlich Rolfs Verteidiger Oscar de Besche. Die Aufgabe eines Verteidigers besteht darin zu verteidigen, weshalb es keine Überraschung ist, dass er der Staatsanwaltschaft gegenüber Rolfs Situation auf die Spitze trieb und sie zu einer Wahl zwischen einer Zusage zur Arbeit in Deutschland oder einer Inhaftierung im Konzentrationslager machte. Und inmitten dieses Dilemmas wurde dann bekanntgegeben: „Wenn er arbeitete, sollte sein Bruder Erleichterungen erfahren und möglicherweise freigelassen werden. ${ }^{10}$.

Zugrunde legte der Verteidiger das, was Rolf ihm während des Gerichtsverfahrens geschrieben hatte, in einer Situation, in der er unter Druck stand und sich detaillierter ausdrückte als in Interviews, nachdem er zu allem Abstand gewonnen hatte. Dabei berichtete er auch von NEBB-Kollegen, deren Freilassung er zu erreichen versucht habe:

„Was für mich die Frage entschied, für die Deutschen zu arbeiten oder abzusagen, war, dass sie versprachen, meinen Bruder freizulassen. Wenn mein einziger Bruder, der zu zehn Jahren Strafarbeit verurteilt worden war, dort unten sterben würde (er war im Gefängnis viel krank gewesen), hätte ich mich für immer an seinem Tod mitschuldig gefühlt. Ich glaube auch nicht, dass mein Vater, der sehr niedergeschlagen war, einen solchen Verlust überlebt hätte. Da ich gleichzeitig wusste, dass die verlangte Arbeit nicht kriegswichtig war, kann ich nicht verstehen, dass ich überhaupt eine Wahl hatte. Zum Schluss möchte ich nur erwähnen, dass die Deutschen auch versprachen, 13 Mann von (...) und (...) freizulassen, die auch im Gefängnis saßen. Ich habe viel an dieser Sache gearbeitet, und letztendlich ist es mir gelungen, zwei Männer freizubekommen, (...) und (...).“11

Nachdem er aus dem Schriftstück zitiert hatte, fügte de Besche hinzu: „Ich glaube, wir werden uns darüber einig sein, dass es hier keine besondere Wahl gab.“ Des Weiteren fügte er hinzu: „Es kann angemerkt werden, dass Viggo Widerøe nicht freikam, schrittweise erhielt er jedoch verschiedene Erleichterungen von seinem Zuchthausaufenthalt und überlebte den Krieg." In Verbindung mit seinem Studium der Verfahrensakten interviewte Tor Brustad Viggo bezüglich des Verhältnisses zum Bruder. Seine Eindrücke fasst er viel folgt zusammen:

„Es schien beständig durch, dass sie einander nahestanden. Bei Viggo erhielt ich jedoch den Eindruck, dass er enttäuscht darüber war, dass Rolf in eine 
NS-Familie eingeheiratet hatte. Dass dies seiner Meinung nach zu weit ging, dass Rolf dahingehend enttäuscht habe. Allerdings hält brüderliche Loyalität sehr viel aus. Ich glaube, er bewunderte den großen Bruder auch sehr für alles, was dieser erreicht hatte. Eigentlich glaube ich, dass er das Verhältnis zu Rolf während des Krieges und kurz danach im tiefsten Inneren für problematisch hielt, speziell wegen Rolfs Tätigkeit in Deutschland. Zeitweise muss das Verhältnis zwischen ihnen angespannt gewesen sein, richtig stark, aber sie entschieden sich, nach vorn zu schauen. Sie wollten Frieden haben, sie wollten ein gutes Verhältnis zueinander, und ich glaube, das hatten sie. Viggo schien seinen Bruder aufrichtig zu mögen."

Nach diesem Gespräch mit Brustad darüber, dass die Brüder ihre Schwierigkeiten miteinander hatten, dachte ich: Wenn die beiden Häuptlinge sich entschieden hatten, in Frieden miteinander zu leben, will ich es aus Respekt dabei belassen und nicht weiter in der Problemstellung graben. $\mathrm{Zu}$ diesem Zeitpunkt hatte ich den „wichtigen Brief" noch nicht gelesen. Ich wusste nur, dass die Brüder in ihrem Rentnerdasein einander fleißig besuchten, dass ihre Kinder die gemeinsamen Sommer in den 1940er und 1950er Jahren zu den großen Ereignissen ihrer Kindheit zählten - und dass sie als erwachsene Cousins und Cousinen bis heute zusammenhalten. Neugierig auf die Versöhnung, die stattgefunden haben musste, und darauf, ob es faktisch etwas $g a b$, weshalb man sich versöhnen musste, hatte ich ihnen allen meine Fragen gestellt, denn es konnte unmöglich schaden, die Sachen von mehreren Seiten zu beleuchten. Wenn alles so war, wie es sein sollte, dann hielt das brüderliche Verhältnis die Wahrheit aus. Dennoch zögerte ich, darüber zu schreiben; der Respekt gegenüber dem Privatleben anderer hielt mich zurück.

Dann aber bekam ich den Brief. Machte kehrt - aus Respekt. Das musste rein. Dass die beiden während des Krieges und in der ersten Zeit danach ein schwieriges Verhältnis hatten, ist Teil des Bildes und nichts, was es zu verbergen gilt. Denn sie waren längst versöhnt, vor der Biografie und vor dem Brief, bevor sie alles wussten. Und hätten sie es nicht schwer gehabt, dort, wo sich jeder auf seiner Seite befand, dann hätte ich sie nicht ernst nehmen können. Und - als wäre es eine Überraschung: Auch für die drumherum war es nicht immer leicht. Nein, selbstverständlich nicht. Wie könnte es?

Die Schlussfolgerung lautet: Die Brüder hatten, sowohl jeder für sich als auch zusammen, während des Krieges viel durchgemacht. Ihr Verhältnis war auf eine harte Probe gestellt worden. Es galt, in Freundschaft weiterzumachen und das Schlimme hinter sich zu lassen. Dafür braucht man nicht alles zu verstehen. Das war es, was eigentlich in dem Brief stand. Die Versöhnung war für die beiden nicht leicht erkauft, aber selbstverständlich. Das, 
was in dem Brief stand, brauchten sie nicht zu wissen. Der Inhalt bestätigte jedoch, dass ihre Entscheidung zur Versöhnung richtig war. Und die Nachwelt versteht ein wenig mehr, was bedingungslose Versöhnung ist und was sie Gutes mit sich bringen kann.

\section{Mit offenem Visier}

So viel, was in so vielen Jahren nicht gesagt wurde. So viel Freundlichkeit. Wir stehen Menschen gegenüber, die leben, wie sie es gelernt haben: „zuerst - nett voneinander denken“, wie viele es ausdrücken.

Mit so viel Rücksicht und Schweigsamkeit und zeitweise ohne eine Miene zu verziehen, fügt es sich sogar ins Bild, dass Rolf 1947 nicht aus der Schweiz zur Beerdigung seines Vaters nach Hause gefahren ist. Gleichzeitig aber hat es mich auch verwundert. So gleichgültig, so ohne Fürsorge für seine Mutter, dass er nicht zur Beerdigung nach Hause fuhr? So respektlos gegenüber seinem Vater, mit dem er eigenen Aussagen zufolge meilenweit Ski gefahren war? Wandertouren und Urlaubsreisen unternommen hatte. Nein, das Bild vom Gefühllosen stimmte irgendwie nicht. Tatsache aber ist auf jeden Fall, dass er im Januar, einige wenige Monate nach dem Umzug in die Schweiz, nicht zur Beerdigung seines Vaters nach Norwegen gefahren ist. Er, der er aus einer guten Familie stammte, wo man viel Umgang miteinander pflegte, nahm nicht an der Beerdigung des Vaters teil. Ein naheliegender Gedanke verschafft sich Gehör: Stand er außen vor? War er beschämt? Hatte er Angst vor dem Gerede der Leute? Angst davor, was die Familie sagen würde? Oder war er so fertig mit Norwegen, dass er den Gedanken, dorthin zu fahren, nicht aushielt? Fehlte es ihm als ältestem Sohn an Anstand? Schließlich war es der Vater, der ihm die Ausbildung im Ausland ermöglicht hatte. Konnte er es sich finanziell nicht leisten? Nicht so abwegig nach einigen Jahren ohne Lohn. Ging er nicht zu Beerdigungen? Schließlich wurde über seinen Bruder Viggo gesagt, dass er nicht der Typ war, der zu Beerdigungen ging. Aber Rolf, dachte er so? Kümmerte er sich nicht, sah er nur sich selbst, ohne an andere zu denken? Nach dem Verhalten allein beurteilt, kann es so aussehen, ja.

Aber dann war da dieses Widerøesche, nicht zu früh eine negative Meinung zu fassen. Denn vielleicht gibt es Dinge, die man nicht weiß. Erneut kommt Hilfe in Form von Briefen herbei, zwei fast 70 Jahre alten Schreiben vom Sohn an die Mutter. Der erste vom Todestag des Vaters, als das „Visier“ oben war, datiert auf den 23. Januar 1947. 


\section{Übersicht}

Liebe Mama!

In diesem Augenblick erhielten wir das Telegramm über Papas Tod. Es ist merkwürdig, dass er weg ist, gar nicht zu glauben. Ja, wir werden ihn immer sehr vermissen, am meisten du, glaube ich. Es macht so wehmütig, Papas letzten Brief mit deiner Notiz zu erhalten; das war beinahe wie ein letzter Gruß von ihm, allerdings glaubte ich damals doch nicht, dass alles so schnell gehen würde. - Das muss eine harte Woche für euch zu Hause gewesen sein. Hier unten konnten wir warten und hoffen. Heute erhielten wir Elses Brief, der erklärt, wie sich alles zugetragen hat, und wir hatten ein wenig Hoffnung, dass es vorübergehen würde. Als es aber heute Abend um 9 Uhr an der Tür klingelte, wussten wir beide, was es war. -

Es ist seltsam, jetzt an die letzte Zeit zu Hause zurückzudenken, als ich mit Papa zusammen war. Er saß am Schreibtisch und ordnete seine Briefmarken, ich arbeitete und dann erzählte er mir einige Dinge aus seiner Jugend. Von der ersten Zeit, als er nach Kristiania kam, von seiner Arbeit bei Eide, von seinen Wanderungen in der Nordmarka und von zu Hause. Im Grunde war ich ihm nie zuvor so nahegekommen, er sprach so nett und kameradschaftlich und ich bin richtig froh über die letzte Zeit, als ich zu Hause war. -

Jetzt habt ihr vermutlich viel zu tun, bis alles überstanden ist, aber ich hoffe, dass Viggo, wie er mir schrieb, das mit Papas Geschäftsverbindungen regelt, und für das Übrige bekommst du sicher Hilfe von Edel, Else und Grethe. Du musst schnell schreiben, wenn du möchtest, dass ich zur Beerdigung nach Hause komme. Wenn das überhaupt möglich ist (ein Platz im Flugzeug ist nicht leicht zu bekommen), ist es auf jeden Fall keine leichte Sache. In dem Fall muss einer von euch eine Strecke kaufen, Rückflugticket für mich und mir diesbezüglich telegrafieren (die Bezahlung werde ich in dem Fall regeln, wenn ich nach Hause komme).

Es ist entsetzlich schwer für mich, jetzt von hier unten wegzukommen, da wir gerade an einigen sehr entscheidenden Versuchen arbeiten.

Grüße alle anderen von mir und richte Else und Viggo Dank für den Brief aus.

Ich bin nicht imstande, viel mehr zu schreiben, weil ich an so viel denken und an so viel zurückdenken muss.

Herzliche Grüße dein Rolf

Am oberen Rand finden sich zwei Zusätze:

\section{Übersicht}

Es gibt keine telefonische Verbindung nach Norwegen, aber nach Schweden. Meine Nr. ist 335232, aber ich gehe davon aus, dass Viggo jetzt bei euch ist.

Der Brief, auf den Papa gewartet hat, betraf die Gleichung. Gehe davon aus, dass er angekommen ist und dass Viggo das klären kann. 
Ich glaube, die Mutter hat es verstanden. Zynismus und Gefühllosigkeit sind keine zutreffenden Kategorisierungen mehr. Und sollte seine alte Mutter jemals an der Gesinnung ihres Sohnes gezweifelt haben, und sollte der Brief nicht deutlich genug Fürsorge und warme Gefühle demonstriert haben, muss zumindest der nächste Brief sie nachdrücklich überzeugt haben. Geschrieben wurde er neun Tage später, nachdem er den Bericht seiner Schwester von der Beerdigung erhalten hatte.

\section{Kinder im Bett}

Dieser Brief ist länger als der erste. Rolf muss viel auf dem Herz gehabt haben, ihr lieber kleiner, großer, tüchtiger Junge, dort in der fernen Schweiz:

\section{Übersicht}

Giesshübelstr. 114, Zürich 1/2-47

Liebe Mama!

Jetzt ist die Unruhe der Woche vorüber, die Kinder sind im Bett und ich möchte mich gern mit dir unterhalten. Ich habe gerade die letzten Briefe hervorgeholt (wir bewahren sie alle auf). Elses Brief, den wir am Montag erhalten haben, deinen Brief, den du am Montag geschrieben hast, und einen langen Brief von Onkel Marius, den wir heute bekamen, in dem er von der Beerdigung berichtet. Es ist ein seltsames Gefühl, so weit weg zu sein, hier in ganz völlig Umgebung auch die ganze Beerdigung und die Stimmung beim Abendessen zu erleben. Ich glaube, ich sehe den ganzen Tisch und alle Gäste vor mir, als er seine Rede hält, es ist nur eine Sache, die ich mir nicht vorstellen kann, und das ist, dass Papa beim Abschiedsfest nicht anwesend ist. Er gehörte so sicher mit zum Bild - ich meine beinahe ihn ganz oben am Tisch sehen zu können, wenn er nickte, lächelte und alles tat, damit es eine nette Gesellschaft wurde. Ja, es ist ganz unglaublich, dass er weg ist und ich ihn nicht mehr sehen und nicht mehr seine Briefe bekommen soll. Als ich ihn das letzte Mal sah und mich von ihm verabschiedete, dachte ich noch, dass die Zukunft unsicher sei, aber du weißt, man sträubt sich dagegen, das Schlimmste zu denken, und ihm gegenüber erwähnte ich natürlich nichts. -

Onkel Marius schreibt, dass du bei all dem in dieser Zeit gut Hilfe bekommst, aber ich verstehe durchaus gut, dass du es nicht leicht hast. Du warst es schließlich, die Papa am besten kannte, und für dich muss es wohl beinahe so sein, als würdest du einen Teil von dir verlieren. Indessen denke ich, dass es ein Trost für dich sein muss, dass er einen so leichten und schönen Tod hatte. Es war wohl beinahe so, als habe er seine Taten hier auf Erden vollbracht und zöge sich nun zurück, um anderen nicht zur Last zu fallen, ja, es würde mich keineswegs wundern, wenn er so gedacht hat - er dachte doch ausschließlich an das Wohl der anderen, nie an sich selbst. - 
Nun hoffe ich nur, dass du alles mit Fassung trägst. Es nützt nichts, den Mut zu verlieren, und wie ich früher einmal zu dir gesagt habe, glaube ich, dass der, der uns verlassen hat, es so am liebsten sieht. Es ist vermutlich viel, mit dem du dich jetzt beschäftigen und worauf du jetzt achten musst, und ich kann mir denken, dass das einen klaren Kopf und einen gefassten Geist erfordert. Ich bin froh, dass Viggo im März in die Stadt kommt, ich habe ihm geschrieben und ihm geraten, Papas Geschäfte selbst fortzuführen und nicht die große Reputation zu verschwenden, die Papa sich über ein langes Arbeitsleben hindurch aufgebaut hat.

Onkel Marius schrieb, dass er dich öfter besuchen wolle, und ich glaube, daran wirst du viel Freude haben, denn ich finde, er ist umgänglich und nett, ja, ich glaube, von den Brüdern mag ich ihn am meisten.

Wie du dir vermutlich denken kannst, nimmt die Arbeit hier unten mich vollends in Anspruch. Als ich das erste Telegramm über die Herzattacke bekam, dachte ich sofort, ob ich nicht versuchen solle, ein Flugticket nach Hause zu bekommen, hielt es jedoch für das Beste, genauere Details abzuwarten. Viggos Telegramm beruhigte mich etwas, und plötzlich war es zu spät.

Ich bin froh, dass du nicht wolltest, dass ich als der älteste Sohn bei der Beerdigung anwesend bin. Was mir etwas bedeutet hätte, wäre ihm auf Wiedersehen zu sagen, als er am Leben war - mich von seiner Bahre zu verabschieden, ist nicht dasselbe. Wie ich außerdem schrieb, arbeite ich jetzt auf Hochtouren mit meinem Transformator, wir hoffen, ihn am 1. Juni fertig zu haben. Wenn aber die Messungen, die ich derzeit vornehme, nicht richtig gemacht werden (und sie sind keineswegs einfach), riskiere ich, dass ein Jahr Arbeit vergebens war und wiederholt werden muss. Deshalb war ich am Abend so erschöpft, dass ich schlicht und einfach nicht die Gedanken für einen vernünftigen Brief an euch zu Hause sammeln konnte, und das ist der Grund, warum ich erst jetzt schreibe.

Hier unten geht es uns allen gut. Wie sind alle gesund und munter, und das ist im Grunde ziemlich seltsam, weil es hier unten seit gut einer Woche ziemlich kalt ist. Es waren bis $\mathrm{zu}-17^{\circ} \mathrm{C}$, und an diesen Tagen hatten wir bei uns im Wohnzimmer nur $12-13^{\circ} \mathrm{C}$. Es begann in der Regel morgens mit $8-9{ }^{\circ} \mathrm{C}$ und stieg den Tag über langsam auf ca. $11^{\circ} \mathrm{C}$ um 3 Uhr und $12-13^{\circ} \mathrm{C}$, als ich gegen $1 / 27$ nach Hause kam. Das war eine schwierige Zeit für Ragnhild, die doch den Großteil des Tages zu Hause ist. Im Büro haben wir es gut und warm, aber im Labor sind es nur $10-11{ }^{\circ} \mathrm{C}$, und dort renne ich die meiste Zeit im Wintermantel umher. Jetzt sieht es aber so aus, als hätte die schlimmste Kälte nachgelassen, und heute war es richtig frühlingshaft mit Sonne und nur einigen wenigen Kältegraden. - Das Auto nutzen wir nur an den Sonntagen, allerdings waren wir, seit der Schnee kam, fast jeden Sonntag mit den Ski unterwegs. Letzten Sonntag war übrigens nur wenig Schnee, dort wo wir waren, weshalb im Wesentlichen Rolf und ich uns versuchten - er ist mittlerweile richtig flink darin, im Winter auf der Piste zu stehen.

Ansonsten mühen sich die Kinder heftig mit der Schule ab. Sie haben lange Schultage und wenig frei, aber abgesehen davon, dass sie wenig raus an die Luft kommen, glaube ich, dass es ihnen nicht schadet. Ich habe jetzt angefangen, Arild das Lesen beizubringen, aber wir sind noch nicht so weit gekommen, dass man damit angeben könnte. Unn hingegen müht 
sich mit unglaublich schweren Aufgaben und ist von morgens bis abends nur mit Schule, Nähen und Gymnastik (um ein bisschen in Form zu kommen) beschäftigt. Lasst es euch alle richtig gut gehen, und herzliche Grüße an dich und Else von deinem Rolf.

PS:

Ich wäre sehr dankbar, wenn du eine kleine persönliche Sache von Papa für mich aufbewahren könntest, sodass ich eine bestimmte kleine Erinnerung an inn habe.

Hier schreibt nicht der Starkstromingenieur oder der begabte Schüler mit Doktortitel und Spitzenjob im europäischen Wirtschaftsleben. Auch nicht der Mann mit einem Bußgeld wegen Landesverrats und einem seltsamen Aufenthalt in Deutschland während des Krieges in seinem Lebenslauf. Hier ist es der Junge, der älteste - jetzt 44 Jahre alt, dreifacher Vater, mitten im Leben und in Zeitnot, der in einer zugigen Dreizimmerwohnung in Zürich hockt, nachdenklich und vertraut. Sich Offenherzig äußert über Stress auf der Arbeit und Stress zu Hause und der sich nach Mühe und Anstrengung endlich hinsetzen und seine Gedanken für einen Brief „nach Hause" sammeln kann. Der sich Sorgen macht um die zu Hause und um seine eigene Familie. Der die Briefe aus Norwegen aufbewahrt und eine Großmutter erfreut, indem er von den Enkelkindern erzählt, wie weit er damit gekommen ist, Arild das Lesen und dem kleinen Rolf das Skifahren beizubringen. Versucht, vernünftig zu sein, Hoffnungsschimmer in der Trauer zu finden, um sowohl die Mutter als auch sich selbst zu trösten. Der von dem Großen und dem Kleinen schreibt. Dem, was war, und dem, was kommen wird. Dieser Brief beinhaltet ein ganzes Leben und eine ganze Familie. Geschrieben in einer Stunde, als die Deckung fallen gelassen wurde. In einer Sprache, weit entfernt von den knappen, einer Legende gleichenden Sätzen der Biografie, die mitunter den Gedanken aufkommen lassen, er sei oberflächlich gewesen.

Und die alte Dame, die soeben Witwe geworden ist, in Vinderen sitzt und liest - sie wäre wohl keine Mutter, wenn bei diesen Zeilen nicht dächte, dass der Apfel doch nicht so weit vom Stamm gefallen ist. Das hätte auch ihr Theodor schreiben können. Und dann denkt sie an all die Male, als er die Jungs mit in die Marka nahm, an all die Stunden am Kamin, wenn sie bei Freunden mit gleichaltrigen Kindern zu Besuch im Wochenendhaus waren. So, als wäre es gestern gewesen. Wie kurz ein Leben ist. 


\section{Schweizer Pflichten}

Nachdem er sich seit Herbst in der Schweiz niedergelassen hatte, war es für Rolf Schlag auf Schlag gegangen. Seine erste Aufgabe bei Brown Boveri, das Betatron für das Krankenhaus in Zürich, befand sich in diesem Frühjahr in der entscheidenden Phase, und es stand einiges auf dem Spiel. Er hatte viel zu verteidigen und viel zu beweisen. Den Chefs von Brown Boveri, die an ihn glaubten und ihm die Möglichkeit gegeben hatten, in der Schweiz ein neues Leben anzufangen. Der Familie, die sicher das eine oder andere über ihn gedacht hatte, nicht zuletzt dem Bruder Viggo. Zudem wissenschaftlich. Jetzt sollte er demonstrieren, dass er wirklich die Maschine bauen konnte, deren Prinzip er sich ausgedacht hatte. Auch wirtschaftlich.

Er trug Verantwortung für Frau und Kinder. Die entwurzelt und in ein neues Land versetzt worden waren. Mit Geld stand es nach dem Umzug so lala. Er hatte 30 Patentrechte verkaufen müssen, um das Bußgeld an den norwegischen Staat bezahlen zu können. Möglicherweise hatte der Schwiegervater mit Geld ausgeholfen, das meinen zumindest einige. Andere glaubten das nicht, dieser hatte schließlich selbst genug Probleme. Oder sein eigener Vater könnte eingesprungen sein. Genau das hatte er bereits zu einem früheren Zeitpunkt getan. Später zahlte der Sohn alles zurück, mit Zinsen. Nach einigen Jahren mit Familiengründung und Hauskauf beglich er die Schulden während der letzten Kriegsjahre in drei Raten zurück: 1500 Kronen im Juni 1943, 2500 Kronen im April 1944 und den Rest, 15.000 Kronen, im März 1945 - als er die letzte Bezahlung von Theodor Hollnack erhalten hatte.

Der Tod des Vaters kam plötzlich. Nur zehn Tage zuvor hatte er Rolf von „einer ordentlichen Klemme“ geschrieben, in die er geraten war, da „die Steuerveranlagung so unverschämt“ sei: „Sie wollen mich für zehn Jahre nachträglich besteuern für die 19.000 Kronen plus 2900 Kronen Zinsen, die du mir für Auslagen, die ich für deine Ausbildung hatte, gezahlt hast.“ Seinen „anderen Kindern gegenüber, die nicht so eine teure Ausbildung erhalten hatten“, habe er es als „richtig“ empfunden, dass Rolf die Kosten, die seine Ausbildung den Vater gekostet hatte, zurückzahlte. Er hatte die Forderung jedoch erst dann als Einnahme aufführen wollen, nachdem 1945 alles einbezahlt war. „Die Zinsen sind jedoch von 1920 an aufgelistet, wo die Leihe begann“.

„Lieber Papa!“, schrieb Rolf am 17. Januar 1947 und meldete sich mit Aufstellungen über Hypotheken- und andere Schulden zurück, bezahlt und unbezahlt, sowie mit Zahlen aus Steuererklärungen diverser Jahre. Ebenso 
peinlich davon berührt wie der Vater war, das zu thematisieren, erklärte er weitaus detaillierter als nötig, dass er eine Hypothekenschuld auf das Haus abbezahlt habe, seiner Mutter noch immer 10.000 Kronen schulde und im April 1945 dem Vater 635 Kronen als Zinsen auf abbezahlte Schulden gezahlt habe. Es ist nicht sicher, ob der Brief den Vater vor seinem Tod erreicht hat. Keiner war sich im Klaren darüber, wie krank der alte Mann war, und Rolf rundet den Brief damit ab, dass er bedaure zu hören, dass der Vater wieder ins Bett müsse und sich die Bronchitis nicht gebessert habe, und dann empfiehlt er: "Geh mit deinem Husten zu einem Spezialisten."

Ein Anwalt hilft ihnen bei der Angelegenheit, und Rolf verfasst nach Aufforderung des Vaters eine Erklärung, die ihre Abmachung bestätigt:

„Hiermit erkläre ich, dass ich später, wenn meine Einkommens- und Vermögensverhältnisse es zulassen, Theodor Widerøe nach bester Fähigkeit die Ausgaben, die meinem Studium in Deutschland geschuldet sind, ganz oder teilweise zurückerstatte."

Ja, Ordnung musste sein. Aber einfach war das nicht. Finanziell sind die kommenden Jahre von Steuerproblemen und der Abbezahlung des Bußgeldes an die Entschädigungsbehörde geprägt. Der Verkauf von Aktien, Erbe und Vorschuss aufs Erbe lassen die Rechenaufgabe letztendlich aufgehen. Mit der Klärung der Sache, unter anderem Vollmachten für den Verkauf von Aktien, beauftragt er seinen ehemaligen Verteidiger, den Anwalt de Besche in Oslo. Rolf würde auch gern über die 3500 Kronen verfügen, die er der Widerøe Fluggesellschaft geliehen hatte, sowie die 1500 Kronen für den Bruder, schreibt er dem Anwalt, aber: „Im Fall, dass es nicht passt, will ich weder Viggo noch dem Unternehmen ungern unnötige Schwierigkeiten bereiten, sondern mit diesen Beträgen lieber warten, bis es notwendig wird." Tatsächlich hatte ihm der Schwiegervater früher einmal angeboten, Geld zu leihen, Rolf wusste aber nicht, ob er dazu jetzt die Möglichkeit hatte, zudem glaubte er auch nicht, dass dies notwendig sei. ${ }^{13}$.

Die Finanzen waren eine Sache.

Die andere war, es sich selbst zu beweisen. Die Strahlenbehandlungsmaschine, an der er jetzt arbeitete, sollte rechtfertigen, dass er 1943 nach Deutschland gegangen war. Vielleicht hätte sogar der Vater gewollt, dass er weiter sein Projekt verfolgte, statt zur Beerdigung zu kommen? Vielleicht war er jetzt gefordert, die Möglichkeit zu nutzen, die ihm sein Vater einst dadurch eröffnet hatte, indem er ihn auf eine anständige Technische Hochschule schickte? Vielleicht war das ein angemessenerer Weg, Respekt zu zeigen, seine Pflicht zu tun, seine Verantwortung zu tragen. 


\section{Pendeln zwischen Außenpunkten}

Das Gleichgewicht zwischen all dem zu finden, was im Leben wichtig war, inklusive seines Traums, war etwas, worum Rolfs Gedanken in nachdenklichen Stunden kreisten. Ein ungewöhnliches Wortpaar: Gleichgewicht und Traum. Aber Rolf war sich dessen bewusst, was sowohl die Stärke als auch die Schwäche der Familie ausmachte - die leicht stolze Eigenart. Hier fanden sich starke Persönlichkeiten, Individualisten, Personen mit Integrität auf mehreren Ebenen. Stärke und Ausdauer waren mehreren von ihnen zu eigen, konnten für das Umfeld jedoch eine Herausforderung darstellen, wie er selbst es ausdrückte. Zeitgleich erinnerte er gern daran, dass man den Traum nicht vergessen dürfe.

In der Rede an Ragnhild anlässlich ihrer Goldenen Hochzeit sprach er über das Leben als „Pendeln zwischen Außenpunkten“ und darüber, dass er mitunter das Gleichgewicht verloren habe. Zum Ausgangspunkt nahm er den Comic über Finbeck und Fia, den er im Urlaub im Wochenendhaus von Freunden gelesen hatte, bevor die beiden einander kennengelernt hatten. Der aus dem Amerikanischen stammende Comic heißt im Original „Bringing up father“. „Das heißt ,Vater soll erzogen werden', und jetzt versteht ihr womöglich den Zusammenhang", sagte Rolf und zeigte auf das hinter ihm an der Wand hängende Bild des Haustyrannen. Er gab an, dass fünfzig gemeinsame Jahre viele Herausforderungen mit sich brächten, und konstatierte: „Der Mensch ist das große Unbekannte.“ Darüber hatte er bereits als 15-Jähriger nachgedacht und sich seinem Tagebuch anvertraut. In seiner Rede verwies er nun darauf, dass unter den Gästen zwei Psychiater seien, die sich darauf wohl besser verstünden als er. Anschließend stürzte er sich auf das Phänomen „Männer“:

„Männer gibt es in vielerlei Formen und Facetten. Wir haben die Propheten, die gänzlich von einer fixen Idee besessen sind. Wir haben die, die versuchen, so viel Geld wie möglich zusammenzukratzen. Wir haben die Normalos, die sich vor allem für Fußball und anderen Sport interessieren. Und dann haben wir Tausende anderer Variationen. Künstler, Gärtner und fleißige Ameisen, die Bürostühle durchsitzen. (...) Und mit all diesen wundersamen Wesen sollen die Frauen nun klarkommen und versuchen, sie ein wenig zu bändigen! (...) Man stelle sich zum Beispiel vor, mit einem Propheten verheiratet zu werden; so wie Mohammed. Das muss entsetzlich sein. Den einen Tag zog er nach Jerusalem und flog dort mit seinem Pferd gen Himmel, am nächsten Tag zog er mit dem Schwert in der Hand los, um seine Nachbarn fertigzumachen. Ja, Ragnhild, du kannst froh sein, dass du nicht so einen geheiratet hast. Aber, 
aber, wir Männer haben im Grunde unseres Gemüts wohl ein wenig vom Propheten und der fixen Idee - hier will ich mich selbst nicht ausnehmen. Es gab Zeiten, in denen ich ziemlich monoman war, wo Gedanken und Geist stark begrenzt waren. Aber abgesehen von Tennis habe ich mich nie für Sport interessiert, das ist doch zumindest ein Lichtblick."

Dann nahm er sich die Frauen vor, wobei das noch subtiler wurde, da er nicht behaupten wollte, von Frauen so viel zu verstehen. Sie seien „weitaus unbekannter und unerforschter als die relativ simplen Männer", und dann hätten sie „in einer Ehe viele schwierige Aufgaben“. Sie müssten es nämlich schaffen, das „prähistorische“ Wesen namens Mann „mithilfe kleiner Worte, Andeutungen und Vorschläge - das, was die Schweden als ,gelinde Gewalt bezeichnen“, zu lenken:

„Als Vergleich kann man sich den Mann als alte Lokomotive vorstellen, die Rauch und Dampf spuckt und ständig gefüttert werden muss, die unter Hochdruck arbeitet, mit Tausenden von Lenkrädern und Einstellungen, die ständig mit Geduld eingeölt werden muss, rumpelt und läuft, die launisch ist und leicht aus der Spur gerät. Und die Frau? Sie ist die Lokführerin, die versucht, das Ungeheuer zu beherrschen. Neben dieser nicht ganz leichten Aufgabe obliegt ihr eine Unzahl anderer Schwierigkeiten. Sie muss auch die Nachkommen erziehen, das liegt weit unter der Würde des Mannes, sie muss jede oder jede zweite Woche zum Friseur, um die Haare zu waschen. Und ab und an, wie zum Beispiel hier im Haus, muss sie sich um Geldangelegenheiten kümmern und dafür sorgen, dass ich mein monatliches Taschengeld bekomme."

Auch abschließend blieb er diesem halb humoristischen, halb ernsten selbstironischen Stil treu:

„Wie du aus diesen einzelnen und vollkommen zusammenhanglosen Gedanken verstehen wirst, Ragnhild, schätze ich dich und deine Arbeit - auch mit , bringing up father - sehr. Und wenn ich ab und an knurre und klage, weil das halbe Leben dafür draufgeht, alles Unaufgeräumte aufzuräumen, oder wenn ich mich wie ein Igel sträube, wenn es darum geht, neue Kleidung zu kaufen, oder wenn ich mich entschieden weigere, Hühnchen zu essen, so sind all das nur Zeichen dafür, dass wir die Dinge ein bisschen unterschiedlich betrachten. Das, was mir höchst unwichtig und unnötig erscheint, ist für dich sehr wichtig und bedeutend. Natürlich hast du in der Regel recht, und ich bin dir zutiefst dankbar, dass du bei einem so törichten, prähistorischen Wesen für Sitte und Ordnung sorgst. ${ }^{\text {"14 }}$ 


\title{
In seiner Blase - und außerhalb
}

Als Tunnelblick würde man es heute bezeichnen, wenn Rolf in seine eigene Welt eintauchte, die Betatron-Welt, und hinter sich die Türen schloss. Sich in seiner Blase befand. Im Unterschied zu vielen anderen war ihm das bewusst. Und er verweilte dort. In Stunden mit Damast auf dem Tisch und hohen Gläsern verriet der Festredner, dass er nicht ganz unempfindlich dahingehend war, wie es dem Umfeld ging, wenn der Forscher in ihm am stärksten durchkam.

Eine Person, die ihre Meinung hat und diese durchsetzen will - diese Charakteristik verwendet Professor Tor Brustad für ihn. Ein klein wenig Fachidiot also, auch wenn Brustad es diplomatischer ausdrückt:

\begin{abstract}
„Mein Eindruck ist, dass Rolf im Leben ein großes Interesse hatte, und das war Technologie und die Entwicklung von Beschleunigern. Einzelne würden vielleicht sagen, er war beinahe ein Fachidiot, weil sein Interesse genau dafür so enorm war. Das würde das Ganze wohl etwas auf die Spitze treiben, und das ist nun nicht gehässig gemeint, aber ein Körnchen Wahrheit steckt darin. Er war eine Person, die ihre Meinung hatte, und wenn er einen Beschluss gefasst hatte, dann war es sehr schwer, ihn dazu zu bringen, seine Meinung zu ändern."
\end{abstract}

Fachidiot? Ja, „Idiot“ auf dem eigenen Gebiet und gänzlich Idiot auf allen anderen, wie man kalauert. Fachidiot? Rolf? Ja, aber nicht nur - wobei Brustad nicht der Einzige ist, der diesen Ausdruck verwendet. Besessen von seiner Forschung? An nichts anderes denkend? Nun, seine Kinder sagen das nicht. Aber daran interessiert, ihr zugeneigt, ja. Ein Berufsleben, in dem es kein Fazit gibt, das Kreativität und Neugierde steuert, lädt dazu ein. Und ich glaube, er war sich dessen bewusst. Es ist kaum ein Zufall, dass er, wenn die großen Anlässe nach Reflexion und festlichen Worten riefen, über Gratwanderung, das Pendeln zwischen Gegenpolen, die unterschiedliche Sicht auf Dinge, Grenzen zwischen Menschen, das Einander-in-Schach-Halten, Geduld und Wohlwollen sprach.

Nur Fachmann, keine Gefühle? Noch einmal: Nein. Und sollte der Gedanke doch einmal aufgekommen sein - dass er sich nur für sein Fach interessierte -, war dies endgültig undenkbar, nachdem ich einige seiner privaten Briefe gelesen hatte. Kann man sowohl fachlich hoch engagiert sein und gleichzeitig starke Gefühle haben? Ja, natürlich. Warum nicht? Es handelt sich um dieselbe Fähigkeit zum Einfühlen und zur Anwesenheit, etwas, das einen voll und ganz fordert, Normen und Umfeld übersteigt. 
Das Tagebuch, das er in jungen Jahren schrieb, die Reden, die er hielt. Gespräche, die ich mit Kindern und Enkelkindern, Schwester, Schwager, Schwägerin, Nichten und Neffen führte. Sie belegen, dass es in der Tat möglich ist: „Ein Onkel, den zu besuchen Spaß machte“, sagt ein Neffe. „Wir waren immer willkommen“, sagt ein Schwager. „Vater ,zelebrierte“ den Sonntag regelrecht", sagt sein jüngster Sohn Rolf.

„Früh an jedem Sonntagmorgen pflegte er zu singen, zu pfeifen, Unsinn und Quatsch zu machen, Superlaune zu haben. Das steckte die ganze Familie an. Damals arbeiteten die Leute samstags, am Sonntag aber machte Vater frei. Da unternahmen wir alle zusammen einen Ausflug. Jeden Sonntag. Wir waren damals die Einzigen, die ein Auto hatten, wir fuhren ein Stück, und dann gingen wir zu Fuß oder liefen Ski, absolut jeden Sonntag. Wir Kinder nahmen gern Freunde mit. Sieben Personen im Auto. Er war tüchtig darin, die Familie zusammenzuhalten. Auch wenn wir nach Norwegen fuhren, hatten wir Kinder Freunde dabei. Als wir schließlich älter wurden, waren wir bei den Sonntagsausflügen nicht mehr dabei. Dann waren Mutter und Vater viel mit Freunden zusammen und unternahmen mit denen was. Sie haben immer einen Sonntagsspaziergang gemacht. Solange ich mich erinnern kann. Jeden Sonntag neun Uhr waren sie weg."

Dann erzählt er vom Interesse des Vaters an Pilzen und all den Auslandsreisen mit Kameraden aus Studienzeiten, von denen sie gehört hatten:

„Er sammelte Pilze, erinnere ich mich. Kannte viele verschiedene Sorten. War er nicht sicher, dann probierte er sie. Riskierte etwas. Zu Studienzeiten hatte er unaufhörlich Kameraden aus Norwegen bei sich, Kaare Backer, seinen Bruder Viggo und andere, und da fuhren sie nach Paris, Spanien und Venedig, und sie waren auf Bergkuppen hier im Engadin in Pontresina und müssen einen Riesenspaß gehabt haben."

Wie sein großer Bruder weist er zurück, dass der Vater nur an die Arbeit dachte:

„Ich glaube nicht, dass er nur an die Arbeit dachte. Er mochte die Arbeit sicher sehr und war an allem, was damit zu tun hatte, sehr interessiert. Er interessierte sich für so viel. Bis auf die letzten zwei Jahre vielleicht, wo er einen Schlaganfall gehabt haben muss. Aber bis dahin, war er an allem möglichen interessiert. Ich erinnere mich an seinen 90. Geburtstag, den wir in Oslo, in einem Hotel am Holmenkollen gefeiert haben - sein Freund Kaare Backer war auch da, und der war noch ein Jahr älter. Backer sah nicht 
besonders gut und Vater hörte nicht besonders gut, aber zusammen hatten sie viel Vergnügen. Sie wirkten wie zwei kleine Jungs. Ich glaube durchaus, dass er das Leben genoss, absolut das Leben genoss."

Nur Fachmann, keine Gefühle? Erneut: Nein. So einfach ist der Mensch nicht. So einfach war Rolf nicht. Es wäre ungerecht, das über ihn zu sagen. Er, der seinem Tagebuch anvertraute, dass er sich robust und unangreifbar fühle, wenn er sich nur nicht in der Nähe des Mädchens befand, in das er verliebt war. In ihrer Nähe aber reichte ,ein einziger Blick (...), um mich wahnsinnig zu machen“. Er, der als 44-jähriger Mann seine Mutter freundlich bat, „eine kleine persönliche Sache von Papa für mich aufzubewahren, damit ich eine bestimmte kleine Erinnerung an ihn habe". Er, der nach Norwegen zurückkehren wollte, wenn er „alt, so richtig alt“ war, wie sein Enkel Per gesagt hat. „Allerdings meinte er gewiss nie, dass er alt war.“ So blieb es beim Traum. Und den polierte er.

\section{Über ein halbes Jahrhundert jung und begeistert}

Er war sein Leben lang jung, sagt der Physiker Jan Sigurd Vaagen über Rolf. Niemand auf der Welt ist so sicher, die Lösung für ein Problem zu haben, wie ein 22-Jähriger - oder zumindest, dass man die Lösung finden kann. Denn sie ist da. Keinerlei Anzeichen von Zweifel. Meine Idee ist richtig. Ich werde es hinbekommen. Ich werde eine Maschine bauen, wie sie noch niemand gesehen hat. Ich werde es der Welt zeigen. Mein Glaube wird Berge versetzen. Widerstand stachelt an.

Das ist Rolf. Sein ganzes langes Leben. Er behielt den Pioniergeist, den Enthusiasmus, die Neugierde und den Unternehmungsgeist. Tauchte etwas Spannendes auf, dann griff er danach, behielt seine „Idee“ aber im Hinterkopf. Holte sie hervor und betrachtete sie in einem neuen Licht. Praktische Hindernisse - Bagatellen der Art, dass eine Maschine nicht funktionierte, dass die Technologie versagte, dass die Leute es nicht verstanden -, all das waren lediglich Hindernisse, die man schließlich durchdringen konnte. Den Glauben schmälerte das nicht. Schwächte nicht die Überzeugung, dass das Ziel erreichbar war. Die Jugend sieht klar.

An der Hochschule in Karlsruhe hatte Rolf seine große Idee entwickelt, für die er später berühmt wurde. Der Plan war richtig gedacht. Das Praktische glückte ihm nicht, weshalb es ihm nicht gelang zu beweisen, 
dass die Theorie richtig war. Die Theorie und das Prinzip aber stimmten. Später gelang es anderen. In den USA nahm sich Lawrence der Idee an und baute eine ähnliche Maschine. Die brachte ihm den Nobelpreis ein, dabei war er großzügig und erwies Rolf Anerkennung. Rolf sagte: „Juchhe! Ich hatte recht", zuckte leicht mit den Schultern und entwickelte selbst eine Maschine. Eine leistungsstärkere. Sie war Europas Erste ihrer Art. Anschließend wurden es mehr. Viele mehr. Mit leichten Unterschieden. Dem jeweiligen Bedarf und der jeweils vorhandenen Technologie angepasst. Sie wurden in China, Australien, Russland, den USA und ganz Europa installiert. Das ist seine Karriere. In einer Summe.

Die ganze Welt wollte seine Betatrone haben. Er hätte da aufhören können. Auf dem Gipfel. Etwa 1970. Geehrt. Mit Preisen ausgezeichnet, hätte einige Vorträge gehalten, als Berater fungiert. Er hatte wahrhaftig etwas vollbracht. Museen wollten seine Maschinen. Er war weltweit Thema in Physiklehrbüchern. Er verfügte über breit gefächerte Erfahrung, war in der Industrie in so verschiedenen Feldern wie Strom und Krebs tätig gewesen. Er hätte, solange er wollte und dazu in der Lage war, herumreisen können. Hätte bis zuletzt das Ganze auskosten können. Aber nicht Rolf. Er wechselte die Arena. In den letzten gut 20 Berufsjahren seines Lebens forschte er an den Wirkungen der vom Betatron produzierten Strahlen, was diese mit dem Krebspatienten machten. Er, der ein Leben lang daran geforscht hatte, Strahlen herzustellen, ging jetzt dazu über, ihre Wirkung zu studieren. Das tat er bis weit in seine Achtziger hinein.

Lebenshungrig. Vital. Stur. Ausdauernd. Offen. Ein bisschen „alternativ“. Er nahm seine tägliche Dosis Nahrungsergänzungsmittel, schmierte seine Haut mit diversen Cremes ein, klopfte sich nach einem festen Ritual ab, kurierte sich selbst mit Akupunkturnadeln. Neigte zum Aristokratischen, mochte die Geselligkeit, war in seiner großen Familie in Norwegen eine Art Paterfamilias. Sie rechneten mit ihm, und er rechnete mit ihnen, auch nach 50 Jahren in der Schweiz. Bei allen großen Familienzusammenkünften war er anwesend. Seine Arena war die ganze Welt. Sein Unternehmungsgeist kannte keine Grenzen. Früher nicht und später nicht. Nicht, als er als frischer Technologiestudent einen Artikel über Inflationsanalyse an eine Wirtschaftszeitschrift schickte. Nicht, als er ein Doktorandenstudium an seiner alten Hochschule ablehnte, weil sie nicht auf ihn hören und an dem arbeiten lassen wollte, was er wollte. Nicht, als er durch ganz Europa reiste und selbst hergestellte Relais an die Stromindustrie verkaufte. Nicht, als er in Hitler-Deutschland die Widerøe-Gruppe leitete, umgeben von Nazis und Fantasten, Alliierten, Doppelspionen und Nobelpreisträgern. Oder als 
er auf der Höhe seiner Karriere in der Strahlenphysik in ein neues Fachgebiet wechselte, die Biophysik. Oder als er im Rentneralter sein elternloses Enkelkind adoptierte. Und keineswegs im Alter von 87 Jahren, am Abend des 21. Juli 1989 nach seiner obligatorischen Norwegen-Reise, als er ins Reisetagebuch schrieb: „2810 km gefahren“. Und niemand, der ihn kannte, war erstaunt. Sechs Jahre später sagte einer der Chefs des DESY-Labors in Hamburg: „Rolf ist noch immer voller Ideen, die er an mir austestet. “"

\section{Sonnenenergie und Akupunktur}

Auch nicht überraschend ist, dass er sich in die gesellschaftliche Debatte über Sonnenenergie und die Lagerung von Atommüll stürzte. Sein Schwager Egil Reksten ist darauf bedacht, auch diese Seite von ihm zur Sprache zu bringen:

„Es gibt noch ein paar Sachen, die Sie hören müssen, ein paar Ideen, die er hatte. Die eine dreht sich um kernphysikalischen Abfall. Er sagte, es habe einen Versuch mit der Lagerung unter dem grönländischen Inlandeis gegeben, man habe jedoch nicht tief genug gebohrt. 200 Meter runter, da würde er in Ruhe und Frieden zu einem Binnensee schmelzen, der dann unter dem Inlandeis liege. Dort würde er so und so viele tausend Jahre liegen können und weder Mensch noch Tier schaden. Grönland aber habe auf das Heftigste protestiert.

Dann war da eine andere Sache, eine faszinierende Idee, Energie drahtlos $\mathrm{zu}$ senden, was heute wieder leicht vorangetrieben wird. Er meinte, man könne draußen im All eine Sonnenfänger-Station platzieren, wo die elektrische Energie in Kurzwellenstrahlung oder elektromagnetische Strahlung umgewandelt wird, die auf einen Empfänger in einem Antennengebiet auf der Erde gerichtet wird, und dann könnte man Sonnenzellen im All platzieren, eine große Station mit viel höherer Leistung, als wir sie hier unten haben. Die wäre von Wetter und all sowas unabhängig. Ich glaube, er sprach davon, dass man sicherheitshalber ein Empfängerareal von gut 30 Quadratkilometern haben müsse. Und dort solle diese elektromagnetische Strahlung, Kurzwellenstrahlung, aufgenommen werden, ja, und dann würde sie zu Elektrizität transformiert werden."

"Wann hat er daran gearbeitet? Das klingt sehr nach Jugend?"

„Nein, nein, das war in den späteren Jahren.“

Ich frage den Enkel Per, der zu dieser Zeit bei ihm gewohnt hat, nach anderen „modischen“ Ideen, die Rolf in den 1970er Jahren als Rentner hatte: 
"Stimmt es, dass er etwas alternativ eingestellt war, was Medizin und so etwas betraf?"

„Ja, aus China kam er mit einem ganzen Satz Akupunkturnadeln zurück, zudem hatte er eine Puppe, an der erklärt war, wie man stechen muss, und daraufhin behandelte er sich selbst. Anschließend sagten die Leute, er sei vollkommen verrückt, so etwas zu tun, weil man dafür eine Ausbildung benötige. Er aber war der Meinung, es habe ihm geholfen."

"Was wollte er heilen?"

„Es war etwas mit dem Rücken, Ischias, glaube ich. Er las in der Gebrauchsanweisung, was man tun sollte, und dann machte er es selbst. Ich glaube, er hat es nur einmal versucht. Er begriff wohl, dass das keine so gute Idee war. Im Grunde aber war er immer sehr gesund. Er ist täglich geschwommen."

"Tat er das? Ja, ihr hattet ja einen Swimmingpool."

"Ja, auch im Winter."

"Hackte ein Loch ins Eis und ..."

„Ja, ich erinnere mich, dass ich ihm dabei half, das Eis zu beseitigen. Und einmal hatte er danach sehr schlimme Rückenschmerzen. Er weigerte sich jedoch zu akzeptieren, dass das vom Schwimmen sei. Er behauptete, es läge daran, dass wir Hühnchen gegessen hatten! Und dann aß er sein Leben lang kein Hühnchen mehr. Seither wurde es immer Truthahn genannt und nicht Hühnchen, und alles war in Ordnung."

"Aber es gibt doch keinen Zusammenhang zwischen Hühnchen und Rückenschmerzen?"

„Nein, selbstverständlich nicht, aber 20 Jahre lang wurde das aufrechterhalten. Er lächelte nicht, als er das sagte, also hatte es den Anschein, dass er es glaubte. Aber ansonsten, alternative Medizin, das glaube ich nicht. Homöopathie und so, nein ..."

\section{Für immer zweiundzwanzig}

In vielerlei Hinsicht blieb er ein Leben lang 22 Jahre alt. Stob los, liebte Herausforderungen. Am liebsten neue. Und die Spanne war groß. Man sieht es, wenn man versucht, jedes Jahrzehnt seines Lebens mit einem Etikett zu versehen. Da er 1902 geboren wurde und 1996 starb, folgen seine eigenen Lebensjahre sozusagen dem Jahrhundert:

00: Kind | Zieh nicht an den Leitungen, Viggo!

10: Jugend | Komm mit zum Skifahren.

20: Studium | I have a dream.

30: Stromindustrie | Ich werde das beste Relais der Welt bauen. 
40: Betatron | Ich werde das beste Betatron der Welt bauen.

50: Sozial | Willkommen, ich hoffe, wir haben alle einen netten Abend!

60: Biomedizin | Was aber machen diese Strahlen mit dem Patienten?

70: Adoptivsohn | Komm und setz dich, mein Junge.

80: Reisen |Sehen uns im Sommer auf Skjæløy.

90: Mehr Ehre | Jetzt fehlt mir nur noch der Nobelpreis.

Wenn der Appetit so groß ist und das Engagement alles in Anspruch nehmend, wird es zu einem Lebensstil, sich ständig auf neue Dinge zu stürzen. Jung, hungrig, Pionier, neugierig und durchweg 22 Jahre alt zu sein. Natürlich mit gleitenden Übergängen und es zu schaffen, mehrere Dinge parallel zu tun, wie Vorlesungen für Technologiestudenten zu geben und gleichzeitig weiterhin in der Großindustrie tätig zu sein. Da war die Betatron-Forschung allerdings im Abflachen begriffen. Die Strahlenphysik ging und die Biophysik-Forschung kam.

Das Beständige im Leben waren Frau und Kinder sowie die Reisen nach Norwegen im Sommer mit Halt in Hamburg, um Freunde zu besuchen. In späteren Jahren waren es die Zusammenkünfte an den Samstagen, wenn Kinder und Enkelkinder zum Mittagessen kamen. Und dann im Frühling die Besuche beim Bruder in Spanien. Und die Vorträge auf der ganzen Welt. Und die Sommerferien in Norwegen.

Trotzdem sagen die Leute, dass er Scheuklappen trug. Und ja, ich kann es verstehen. Den Grund dafür, ihn als eingleisig zu bezeichnen. Warum? Er? Der so viel erreicht hat: Großindustrie und Forschung. Ski und Tennis. Tanz, Gesellschaften, Unterricht, Vorträge. Großer Bekanntenkreis, Kollegen, zu denen er ein Leben lang Kontakt hielt, Auslandsreisen bis zuletzt. Und eine große Familie in Norwegen, die noch immer ein enges Verhältnis zu seinen Söhnen pflegt, die heute beide über 70 sind. Er, der seine eigenen Wege ging, der Spuren hinterließ. Diese Familie wird sich nicht einig darüber, ob er eingleisig war oder nicht. Ich bitte Egil und Louise Reksten, den Schwager einzuordnen. Vielleicht, aber nur vielleicht nähern wir uns dem Kern dieses komplexen und komplizierten - und kontroversen - Menschen.

Er:

„Er war eingleisig.“

Sie: „Naja ...“ 
Er:

„Doch, aber er ist, war es doch. Etwas eingleisig. Ja, vielleicht das, etwas eingleisig, es gab nicht so viele Nebengleise. Das ist zumindest mein Eindruck. Aber enthusiastisch. Und gleichzeitig ... Schließlich war er Optimist. Ich glaube, er sorgte sich nicht sonderlich um den Weltuntergang. Wenn er Schmerzen in der Schulter hatte, ging er rein und verabreichte sich 11 Röntgen."

Ich:

„Kurierte er sich selbst?“

Er:

„Er hatte Schmerzen in der Schulter. Ja, er hatte die Idee, dass ...“

Dann holt der Chemieingenieur Papier und Bleistift heran und zeichnet: $\mathrm{x}$-Achse $=$ Intensität, $\mathrm{y}$-Achse $=$ Schaden. „Von denen, die mehr Mainstream sind, wurde nun angedeutet, dass die Entwicklung so verläuft", sagt er und zeichnet weiter: „Je mehr Strahlung, desto größer der Schaden. Also desto gefährlicher. Andere sagten: Nein, es ist im Großen und Ganzen so, dass geringe Strahlung nicht gefährlich ist." Dann zeigt er auf das Diagramm und stellt fest:

„Rolf war der Meinung, die Strahlengefahr sei wahrscheinlich so.“ "Aha?"

„Dass ein wenig Extra-Strahlung wahrscheinlich gut tun würde. Und dass es in Deutschland sogar Ärzte gäbe, die zur Kur Patienten in alte Gruben führten, wo eine Kombination aus Temperatur und Strahlung herrschte. Und das waren ausgebildete Ärzte, keine Quacksalber. Und dann sagte Rolf: Diejenigen, die viel Strahlung abbekämen, seien allen voran Kernforscher, und die lebten um einige Jahre länger als die Bevölkerung als Ganzes. Das sei solches Pfui-Pfui-Gerede."

„So etwas zu sagen, ist politisch nicht korrekt, und wissenschaftlich vermutlich auch nicht?"

„Nein, das ist es nicht, aber es kann gut sein, dass er recht hatte. Ich fand es interessant."

„War er Anhänger dessen, was wir heute als alternative Medizin bezeichnen würden? Ich habe gehört, dass er ein allmorgendliches Ritual hatte?"

"Ja, das kann ich mir gut vorstellen."

"Dachte er auch in Sachen Energie alternativ? Ich denke da an Kernkraft."

„Ja, in hohem Maße. Er war entschieden der Meinung, wir müssten zusehen, uns mit der Kernkraft anzufreunden. Ich glaube, er betrachtete das als eine Art Zwischenstadium, bevor uns eine andere, zum Beispiel Weltallbasierte Energiequelle gelänge.“ 
Der Schwager, Chemieingenieur und ehemalige Konzentrationslagergefangener setzt zu einer begeisterten Erzählung über all die Strahlenbehandlungsmaschinen an, die Rolf gebaut hat, über die Patente und das CERN-Labor, das proppenvoll von starken Elektromagneten und unter der Erde in rasantem Tempo miteinander kollidierenden Teilchen sei, das Rolf in Genf mitbegründet hat. Anschließend wirkte er an einem ähnlichen Zentrum mit, DESY in Hamburg, danach PSI, dem Paul Scherrer Institut bei Zürich, und schließlich GSI, der Gesellschaft für Schwerionenforschung in Darmstadt. Alles zusammen.

Bei Fertigstellung des letztgenannten Instituts war Rolf 67 Jahre alt und befand sich inmitten seiner zweiten Forscherkarriere, die sich der Wirkung der Strahlen widmete - neben dem Direktorenposten bei Brown Boveri, den er noch immer innehatte, und den abendlichen Vorlesungen an der Hochschule. Es ist das Jahr, in dem er die Röntgen-Medaille erhält und es der Forschungswelt langsam aufgeht, dass Rolf bereits als Doktorand ein funktionsfähiges Betatron hätte bauen können, wenn die Ausrüstung zur Verfügung gestanden hätte. Mit all dem hinter sich und um sich sind es noch immer drei Jahre, bis Rolf einen Siebenjährigen ins Haus bekommt. Während der kompletten Kindheit dieses Jungen erhält er weitere Medaillen und Auszeichnungen. Als das Kind erwachsen geworden und ausgezogen ist, wird die Karriere endlich mit internationalem Ruhm als Begründer der Wissenschaft der Teilchenbeschleuniger gekrönt. Es ist das Jahr 1992. Der Mann ist 90 Jahre alt. Mehrere haben versucht, ihn dazu zu bringen, kürzerzutreten. Wie die Söhne berichten, habe man ihm bei Brown Boveri schließlich das Büro weggenommen, ohne dass es half; er arbeitete zu Hause weiter.

Dann sind wir am Beginn des Jahres 1994 angelangt, Weihnachten ist vorüber und Rolf erhält den Brief mit dem Dank für das Buch. Ein weiterer Faktor hat seinen Platz gefunden. Es nähert sich der Moment, zwei Striche unter die Antwort ziehen zu können. Dennoch gibt es viele „Unbekannte“. Die Gleichung geht nicht auf. Denn bei näherem Nachdenken fragt man sich: Wie konnte der Inhalt des Briefes solchen Eindruck machen? Die Brüder waren doch lange vor dem Brief versöhnt. Aber - das ist gerade das Große. Sie wollten Versöhnung, trotz des Schmerzhaften, das sie nicht verstanden. Nicht wegen etwas, das Grund dazu gab.

Vielleicht stimmt es also doch. Für ihn. Dass ein Rest bleiben soll, etwas, worüber man sich doch wundert. Vielleicht soll die Gleichung des Lebens nicht aufgehen. Das Leben soll gelebt werden - nach vorn, in einem dynamischen Prozess, bei dem man die ganze Zeit unterwegs ist, bei dem man die Ohrfeigen und die Siege nimmt, wenn sie kommen, mit dem Verstand und der Stärke, über die man zum jeweiligen Zeitpunkt verfügt. Dass darin 


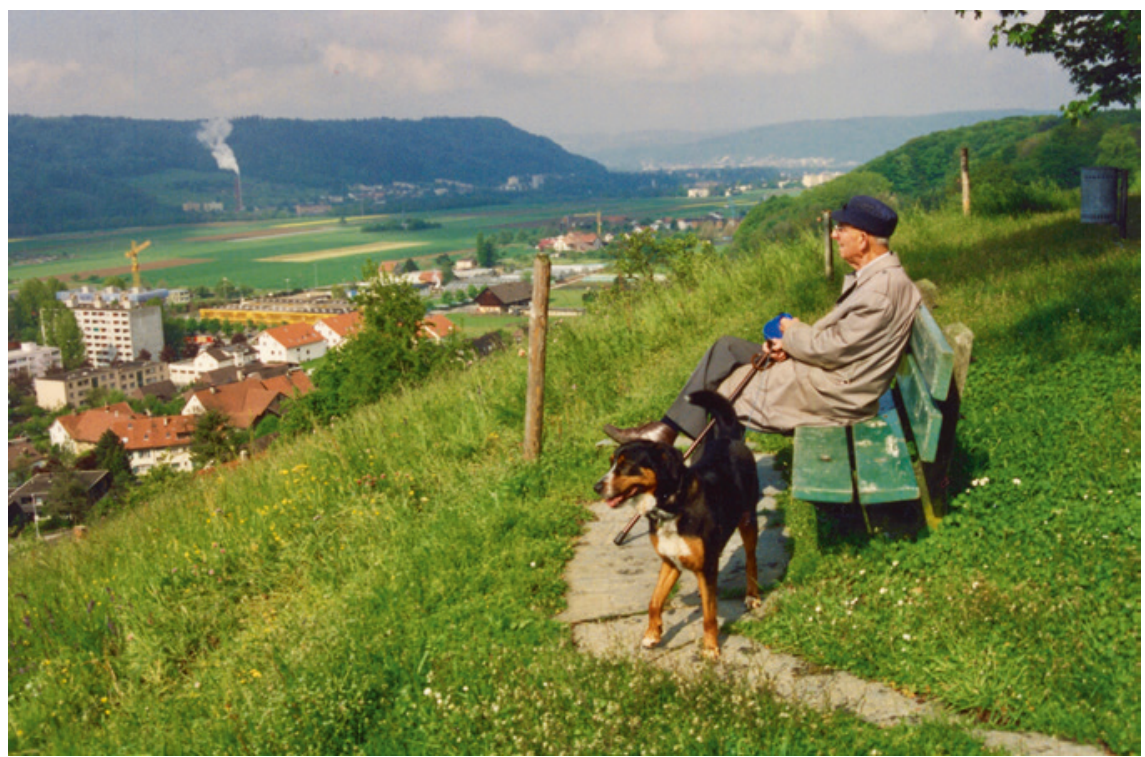

Abb. 7.1 Im betagten Alter unternahm Rolf Widerøe gern Spaziergänge in die nähere Umgebung. Sein Hund war dabei stets an seiner Seite. (Foto @ Pedro Waloschek)

das Geheimnis liegt. Dass ein reiches Leben ein lebendiges Leben ist, in dem die Möglichkeiten vielfältig und überwältigend sind und nie enden - bis es zu Ende ist. Vielleicht war das seine Auslegung. Vielleicht (Abb. 7.1).

In den letzten paar Jahren, als die Gesundheit langsam nachließ, vor allem das Gehör, saß er viel im Schaukelstuhl vor dem großen Fenster im Wohnzimmer. Las, wie er es immer getan hatte. Dort im Lieblingsstuhl sitzend, mit weiter Aussicht über das Tal und die Berghänge des kleinen Ortes, der einer norwegischen Landschaft nicht ganz unähnlich war, fand er noch einmal ein neues Interessenfeld, das Vogelleben vor dem Fenster. Er war fasziniert. Beobachtete. Wunderte sich. Musste es wissen. Mehr wissen. Auf der Fensterbank lag ein Nachschlagewerk über Vögel.

\section{Anmerkungen}

1. Biografie, S. 5.

2. Biografie, S. 63-64.

3. Im Gespräch in Verbindung mit diesem Buch. 
4. Im Gespräch in Verbindung mit diesem Buch, 10. Juni 2010.

5. Im Verbindung mit diesem Buch bezieht sich Tor Brustad auf ein Interview mit Viggo Widerøe in den 1990er Jahren.

6. Die Gespräche erfolgten vor Bekanntwerden des Briefes.

7. Im Gespräch, 21. Dezember 2006.

8. Im Gespräch in Verbindung mit diesem Buch.

9. Im Gespräch in Verbindung mit diesem Buch.

10. Dokument 25 an die Polizeibehörde Oslo und Aker, Abteilung Landesverrat, Viktoria Terrasse 5/7, vom Anwalt des Höchsten Gerichts, Oscar de Besche, datiert 11. März 1946.

11. Das wird auch in einem Verhör Widerøes vom 4. Juli 1945 behandelt, vorgenommen von P.bm. Gustav Dreyer, worin es heißt: „Der Verhörte wünscht hinzuzufügen, dass die Deutschen bei den Verhandlungen in Berlin im Oktober 1943 auch versprachen, einige der verhafteten NEBBFunktionäre freizulassen."

12. Brief von Theodor Widerøe an Rolf Widerøe, 13. Januar 1947, ETHBibliothek Zürich Hs 903:239. Brief von Rolf Widerøe an Theodor Widerøe, 17. Januar 1947, ETH-Bibliothek Zürich Hs 903:239.

13. Brief von Oscar de Besche an Widerøe, 25. Februar 1948, ETH-Bibliothek Zürich Hs 903:239. Brief von Widerøe an Oscar de Besche, 22. März 1948, ETH-Bibliothek Zürich Hs 903:239.

14. Die Feier zur Goldenen Hochzeit fand am 23. September 1984 statt, der eigentliche Hochzeitstag war aber der 14. November.

15. Gustav-Adolf Voss, Leiter der Beschleuniger-Division im DESY-Labor: „A Personal Perspective og High Energy Accelerators“, 1996 IEEE. 
Open Access Dieses Kapitel wird unter der Creative Commons Namensnennung - Nicht kommerziell - Keine Bearbeitung 4.0 International Lizenz (http:// creativecommons.org/licenses/by-nc-nd/4.0/deed.de) veröffentlicht, welche die nicht-kommerzielle Nutzung, Vervielfältigung, Verbreitung und Wiedergabe in jeglichem Medium und Format erlaubt, sofern Sie den/die ursprünglichen Autor(en) und die Quelle ordnungsgemäß nennen, einen Link zur Creative Commons Lizenz beifügen und angeben, ob Änderungen vorgenommen wurden. Die Lizenz gibt Ihnen nicht das Recht, bearbeitete oder sonst wie umgestaltete Fassungen dieses Werkes zu verbreiten oder öffentlich wiederzugeben.

Die in diesem Kapitel enthaltenen Bilder und sonstiges Drittmaterial unterliegen ebenfalls der genannten Creative Commons Lizenz, sofern sich aus der Abbildungslegende nichts anderes ergibt. Sofern das betreffende Material nicht unter der genannten Creative Commons Lizenz steht und die betreffende Handlung nicht nach gesetzlichen Vorschriften erlaubt ist, ist auch für die oben aufgeführten nicht-kommerziellen Weiterverwendungen des Materials die Einwilligung des jeweiligen Rechteinhabers einzuholen. 